\section{Kidney \\ Blood Pressure Research}

\title{
Comparison of Peritoneal Low-Molecular- Weight-Protein-Removal in CCPD and CAPD Patients Based on C-Terminal Agrin Fragment Clearance
}

\author{
Dominik Steubl $^{\mathrm{a}} \quad$ Marcel Roos $^{\mathrm{a}}$ Stefan Hettwer $^{\mathrm{b}}$ Susanne Angermann ${ }^{\mathrm{a}}$ \\ Ming Wen ${ }^{\mathrm{a}}$ Christoph Schmaderer ${ }^{\mathrm{a}}$ Peter Luppa ${ }^{\mathrm{c}} \quad$ Uwe Heemann $^{\mathrm{a}}$ \\ Lutz Renders ${ }^{\mathrm{a}}$
}

${ }^{a}$ Abteilung für Nephrologie, Klinikum rechts der Isar, München, Germany; ${ }^{b}$ Neurotune AG, SchlierenZurich, Switzerland; ' Institut für Klinische Chemie und Pathobiochemie, Klinikum rechts der Isar, München, Germany

\section{Key Words}

C-terminal agrin fragment - Peritoneal dialysis - Residual renal function - Biomarker - Low molecular weight protein $\cdot$ Clearance

\begin{abstract}
Background/Aims: This study compares the peritoneal elimination of the low-molecularweight-protein (LMWP) C-terminal agrin fragment (tCAF, size $22 \mathrm{kDa}$ ), a promising biomarker for kidney function, in continuous cycling peritoneal dialysis (CCPD) and continuous ambulatory peritoneal dialysis (CAPD). Methods: 103 sets of serum, 24h-urine and dialysate samples were obtained in 15 CCPD (63 sets) and 11 CAPD (40 sets) patients. Total, renal and peritoneal substrate removals/clearances were measured/calculated for tCAF, creatinine, blood-ureanitrogen (BUN), cystatin $C$ and albumin and correlated with the peritoneal transport type. Results: Serum und urine concentrations of all biomarkers did not differ between both groups, urinary substrate removal was higher in CAPD patients for all biomarkers due to better residual renal function. Peritoneal substrate removal of tCAF and albumin were significantly higher in CAPD (tCAF: 35.3 vs. $19.3 \mu \mathrm{g} / \mathrm{d}, \mathrm{p}<0.001$; albumin: $4.3 \mathrm{vs.} 3.7 \mathrm{~g} / \mathrm{d}, \mathrm{p}=0.001$ ), whereas cystatin C and creatinine did not differ between CAPD and CCPD (cystatin: 7.7 vs. $6.1 \mathrm{mg} / \mathrm{d}$, $p=0.08$, creatinine: 423.9 vs. $456.7 \mathrm{mg} / \mathrm{d}, \mathrm{p}=0.241$ ). BUN was better removed by CCPD (4846.6 vs. $3393.4 \mathrm{mg} / \mathrm{d}, \mathrm{p}<0.001)$. CAPD patients with high-transporter characteristics had a higher peritoneal tCAF removal compared to high-average-transporters ( $49.8 \mathrm{vs} .28 .4 \mu \mathrm{g} / \mathrm{d}, \mathrm{p}<0.001)$, no differences could be detected in CCPD patients between these groups. CAPD patients using icodextrin twice/day had higher peritoneal clearance of tCAF compared to once daily
\end{abstract}

D. Steubl and M. Roos contributed equally to the work and therefore share first authorship. 


\section{Kidney Blood Pressure Research}

Kidney Blood Press Res 2016;41:175-185

DOI: 10.1159/000443419

Published online: March 10, 2016

(C) 2016 The Author(s). Published by S. Karger AG, Base

www.karger.com/kbr

(4.4 vs. $2.8 \mathrm{l} / \mathrm{wk} / 1.73 \mathrm{~m}^{2}$ body-surface-area, $\mathrm{p}<0.001$ ). Conclusions: CAPD was superior to CCPD concerning peritoneal tCAF removal. This finding was pronounced in high-transporters and CAPD patients using icodextrin twice daily.

(C) 2016 The Author(s)

Published by S. Karger AG, Basel

\section{Introduction}

End stage renal disease (ESRD) is an increasing problem both in industrialized and developing countries. Once there is an indication for renal replacement therapy, transplantation, hemodialysis (HD), as well as automated peritoneal dialysis (APD) and continuous ambulatory peritoneal dialysis (CAPD) are the current treatment options [1]. The standard modality of APD is performed as automated peritoneal dialysis overnight and an additional peritoneal filling during the day, called continuous cyclic peritoneal dialysis (CCPD). While CCPD and CAPD are equivalent with respect to mortality and technical failure [2-4], CAPD appears to have advantages over APD/CCPD concerning sodium removal as well as conservation of residual renal function [5-7].

There is an ongoing debate if the measurement of small-solute clearances (e.g. urea or creatinine, [8]) is sufficient to define the adequate dialysis dose [9]. Furthermore, the effect of the removal of low-molecular-weight-proteins (LMWP, a group of molecules with a molecular mass of 500 to $60000 \mathrm{Da}$ ), on outcome remains unclear. There is a limited number of data on the difference of peritoneal LMWP clearance between CCPD and CAPD. However, it is widely accepted that the peritoneal clearance of LMWPs primarily depends on the duration of contiuous intracavital filling rather than on the number of dialysate exchanges [10]. Therefore CCPD is regarded as the best APD modality to maintain LMWP clearance.

The peritoneal clearance of molecules decreases with increasing molecular size [11, 12], whereas the contribution of renal clearance increases accordingly. However, a recent cross-over study comparing high-flow CCPD and standard CAPD did not observe any significant differences in peritoneal substrate clearances for molecules up to a mass of beta $^{2}$-microglobuline (11.8 kDa, [13]).

Recently we showed that serum levels of total C-terminal agrin fragment (tCAF), a $22 \mathrm{k}$-Da protein derived from agrin, correlated with kidney function in renal transplant and CCPD patients $[14,15]$. The finding in the latter study was primarily due to the low contribution of peritoneal clearance to the total clearance of tCAF.

The present study evaluated differences in peritoneal removal of the LMWP tCAF between CCPD and CAPD patients, also evaluating the influence of transport type on removal rates.

\section{Material and Methods}

This prospective, observational, non-interventional study was approved by the local Ethics Approval Committee (Klinikum rechts der Isar, Technische Universität, Munich, Germany). All patients enrolled gave their informed written consent. 15 CCPD and 11 CAPD patients without acute illness or treated peritonitis during the last six months were enrolled. They were on their dialysis routine for at least one month without alteration of the dialysis prescription.

APD patients received tidal continuous cyclic peritoneal dialysis (CCPD) treatment with glucose (either $1.36 \%, 2.27 \%$ or $3.86 \%$ ) and/or amino acid solutions overnight, a long day dwell with icodextrin and a Baxter HomeChoice Pro Cycler (Baxter International, Deerfield, IL, USA). CAPD patients received treatment with 1-3 fillings of glucose (1.36\% or 2.27\%) and 1-2 fillings of icodextrin (table 1). Within 1.5 years 103 sets of serum, 24-hour-urine and 24-hour-dialysate samples were obtained from these 26 patients (median 4 sets, table 1). tCAF, creatinine (Cr), urea-nitrogen (BUN) and cystatin C (CyC) were assessed in all three materials, albumin (Alb) in serum and dialysate. tCAF levels were measured using a commercially available 


\section{Kidney Blood Pressure Research}

Clearance in CAPD vs. CCPD

Table 1. Demographic characteristics of the whole cohort as well as CCPD and CAPD group

\begin{tabular}{lcccc}
\hline & Total $(\mathrm{n}=26, \mathrm{~s}=103)$ & CCPD $(\mathrm{n}=15, \mathrm{~s}=63)$ & CAPD $(\mathrm{n}=11, \mathrm{~s}=40)$ & $\mathrm{p}$-value \\
\hline Number of samples per patient (n) & $4(1 ; 7)$ & $4.5(1 ; 7)$ & $3.5(2 ; 6)$ & 0.165 \\
Ages (years) & $58(42 ; 8)$ & $53(42 ; 89)$ & $59(43 ; 65)$ & 0.151 \\
Gender (male/female) & $12 / 14$ & $8 / 7$ & $4 / 7$ & 0.547 \\
Body-mass-index (kg/m²) & $26.1(17.8 ; 37.7)$ & $26.5(22.3 ; 32.3)$ & $23.4(17.8 ; 37.7)$ & $<0.001$ \\
Distribution volume (l) & $40.0(21.5 ; 63.3)$ & $39.4(26.1 ; 49.5)$ & $36.5(21.5 ; 63.3)$ & 0.735 \\
Body surface area (m²) & $1.9(1.2 ; 2.6)$ & $1.9(1.4 ; 2.2)$ & $1.9(1.2 ; 2.6)$ & 0.571 \\
Serum albumin (g/dl) & $3.7(2.2 ; 4.6)$ & $3.6(2.2 ; 4.6)$ & $3.8(2.9 ; 4.4)$ & 0.155 \\
24h-dialysate inflow (l) & $10.3(1.5 ; 15.7)$ & $10.6(4.7 ; 15.7)$ & $6(1.5 ; 12.6)$ & $<0.001$ \\
24h-dialysate outflow (l) & $10.7(1.9 ; 17.3)$ & $11.5(4.9 ; 17.3)$ & $6.4(1.9 ; 14.2)$ & $<0.001$ \\
24h-ultrafiltration volume (ml) & $725(-525 ; 2591)$ & $1012(-525 ; 2951)$ & $625(-500 ; 2379)$ & 0.011 \\
24h-urine output (l) & $1.1(0 ; 2.8)$ & $0.5(0 ; 2.8)$ & $1.6(0 ; 2.3)$ & $<0.001$ \\
Peritoneal filling volume (l) & $2(0.75 ; 2.5)$ & $2(1 ; 2.3)$ & $1.7(0.75 ; 2.5)$ & 0.02 \\
APD-duration (h) & - & $8(6 ; 10)$ & - & - \\
APD-tidal volume (\%) & - & $70(45 ; 90)$ & - & - \\
APD-dwell time (min) & - & $54(31 ; 86)$ & - & - \\
APD-number of cycles (n) & - & $7(4 ; 9)$ & - & - \\
Number of CAPD-exchanges (n) & - & - & $3(2 ; 5)$ & - \\
Peritoneal transport type (H/HA/LA/L) & $12 / 12 / 2 / 0$ & $7 / 7 / 1 / 0$ & $5 / 5 / 1 / 0$ & 0.986 \\
\hline
\end{tabular}

Data are presented as median with minimum and maximum in brackets; $n=$ number of patients; $\mathrm{s}=$ number of samples; CPD $=$ continuous cyclic peritoneal dialysis; $\mathrm{CAPD}=$ continuous ambulatory peritoneal dialysis

enzyme-linked immunosorbent assay (ELISA) kit (NTtotalCAF Elisa Kit, Neurotune, Schlieren, Switzerland), performed as described for NTCAF ELISA [16]. Cr and BUN were measured by photometric techniques (Cr: normal range $0.7-1.3 \mathrm{mg} / \mathrm{dl}$ in males and $0.5-1.1 \mathrm{mg} / \mathrm{dl}$ in females; BUN: normal range 7-18 mg/dl). CyC levels were assessed using a nephelometric immunoassay (normal range $0.50-0.96 \mathrm{mg} / \mathrm{l}$ ). Alb in serum was measured using a photometric technique, whereas dialysate Alb concentration was assessed using a nephelometric immunoassay. Primary outcome parameters were the comparison of serum, urine and dialysate tCAF concentrations as well as total, peritoneal and renal (24h-urine) removal/clearance $(\mathrm{Cl})$ between the CCPD and CAPD group. Secondary outcomes were the comparison of the same parameters regarding $\mathrm{Cr}$, BUN and CyC between both groups as well as peritoneal Alb loss. Additionally we tested if peritoneal membrane transport type influenced substrate removal. The membrane transport type in PD is defined according to the results of the peritoneal equilibration test (PET) initially described by Twardowski [17]. Categorisation is performed according to the extent of uremic toxins having diffused into the dialysate after a standardized 4-hour dwell. The more the concentration of uremic toxins in the dialysate equalizes the concentration in the blood the faster the peritoneal transport type (dialysate/blood-ratio). Patients are then categorized into high, high-average, low-average and low transport type. We perform PETs using a $3.86 \%$ glucose solution for the long-term night dwell before the PET and for the PET itself [18]. Patients were categorized into the different transport types according to BUN dialysate/blood-ratio.

Weekly peritoneal and renal clearance for all four biomarkers were calculated following the equation: $\mathrm{Cl}=\mathrm{c}_{\mathrm{D}(U)} / \mathrm{c}_{\mathrm{S}} \mathrm{xV} \mathrm{D}_{\mathrm{D}(U)} \mathrm{x}(1,73 / \mathrm{BSA}) \times 7$, where $\mathrm{c}_{\mathrm{D}(\mathrm{U})}$ represents the solute concentration in dialysate (24h-urine), $\mathrm{c}_{\mathrm{S}}$ the serum concentration, $\mathrm{V}_{\mathrm{D}(U)}$ the spent dialysate (24h-urine) volume. Total clearance is the sum of peritoneal and renal clearance. Peritoneal Alb loss was calculated multiplying peritoneal dialysate concentration with the amount of total daily outflow. GFR was calculated as arithmetic mean of renal $\mathrm{CrCl}$ and $\mathrm{BUNCl}$ in $\mathrm{ml} / \mathrm{min}$.

\section{Statistical analysis}

For statistical analysis IBM SPSS 20 and R 2.15.1 (R Foundation for Statistical Computing, Vienna, Austria) programs were used. Continuous data are expressed as median (minimum; maximum), categorial variables are reported in absolute numbers and percentages of the total population. Mann-Whitney-Test (continuous variables) and exact Fisher-Test (categorical variables) was performed to analyse statistical differences between the two groups concerning primary and secondary outcomes as well as demographic/ treatment characteristics. To account for demographic/treatment differences between the CCPD and CAPD group and its impact on peritoneal solute clearance we performed a multivariate linear regression analysis 


\section{Kidney Blood Pressure Research}

Kidney Blood Press Res 2016;41:175-185

DOI: 10.1159/000443419

Published online: March 10, 2016

(C) 2016 The Author(s). Published by S. Karger AG, Base

www.karger.com/kbr

Steubl/Roos/Hettwer/Angermann/Wen/Schmaderer/Luppa/Heemann/Renders: LMWP

Clearance in CAPD vs. CCPD

with the referring biomarker's peritoneal clearance as dependent variable and PD modality as independent variable. In a second step, this regression analysis was adjusted for variables possibly influencing peritoneal clearance: age, gender, BMI, peritoneal ultrafiltration, transport type, the parameter's serum concentration and total urinary excretion as well as for three different comorbidities, malignant, cardiovascular or diabetic disease. All these parameters were defined as independent variables; for all multivariate analyses, continuous parameters were transformed into logarithmic scale except for ultrafiltration (due to some negative values for which the logarithm is not defined). All analyses were done using a two-sided 0.05 level of significance and have not been adjusted for multiple testing due to the limited number of samples.

\section{Results}

\section{Demographic and dialysis treatment data}

CCPD $(n=15)$ and CAPD patients $(n=11)$, did not differ significantly concerning age, gender, body distribution volume (BDV), body surface area (BSA) and serum albumine (Alb) concentrations but only BMI, the latter being higher in the CCPD group (26.5 vs. 23.4, $\mathrm{p}<0.001$, table 1$)$. The primary underlying diseases were glomerulonephritis $(n=9)$, polycystic kidney disease $(n=3)$, diabetes mellitus $(n=5)$, hypertensive nephropathy $(n=5)$, cardiorenal syndrome $(\mathrm{n}=3)$ and amyloidosis $(\mathrm{n}=1)$.

Median 24h-urine volume $1.1(0 ; 2.8) \mathrm{l} / \mathrm{d}$ was significantly lower in the CCPD than in the CAPD group ( 0.5 vs. $1.6 \mathrm{l} / \mathrm{d}, \mathrm{p}<0.001$, table 1 ), resulting in a difference of residual renal function (RRF; 1.8 vs. $4.8 \mathrm{ml} / \mathrm{min}, \mathrm{p}<0.001$, table 2). As expected, $24 \mathrm{~h}$-amount of dialysate used was significantly higher in the CCPD than in the CAPD group (10.6 vs. $6 \mathrm{l} / \mathrm{d}, \mathrm{p}<0.001$, table 1). Accordingly, peritoneal filling volume and ultrafiltration volume were higher in the CCPD group ( 2 vs. $1.7 \mathrm{l} / \mathrm{d}, \mathrm{p}=0.02$ and 1.0 vs. $0.6 \mathrm{l} / \mathrm{d}, \mathrm{p}=0.011$ respectively, table 1 ). Median total kt/V was $2.0(0.8 ; 3.7)$ and comparable between both groups (CCPD 2.07, CAPD 1.92, $\mathrm{p}=0.549)$.

Concentrations, total solute removal and clearances of $t C A F, C y C, C r$ and BUN/peritoneal albumin loss

Serum and urine concentrations of all biomarkers did not differ significantly between the CCPD and CAPD group (table 2). Due to higher RRF the urinary total solute removal and clearance of all biomarkers were higher in the CAPD group (table 2).

The tCAF dialysate concentration was 4-fold higher in the CAPD than in the CCPD group (339.4 vs. 84.7 pM, p<0.001, table 2). Concentrations of all other biomarkers were higher in the CAPD group, although less pronounced compared to tCAF (1.3-, 1.5- and 2.5-fold for BUN, $\mathrm{Cr}$ and $\mathrm{CyC}$ resp., table 2). Total peritoneal removal and clearance of tCAF was significantly higher in the CAPD group (35.3 vs. $19.3 \mu \mathrm{g}, \mathrm{p}<0.001$, 3.3 vs. $1.7 \mathrm{l} / \mathrm{wk} / 1.73 \mathrm{~m} 2 \mathrm{BSA}, \mathrm{p}<0.001$, table 2). In contrary, $\mathrm{Cr}$ and $\mathrm{CyC}$ total solute removal did not differ significantly between the CAPD and CCPD group (423.9 vs. $456.7 \mathrm{mg}$, p=0.241 and 7.7 vs. $6.1 \mathrm{mg}, \mathrm{p}=0.08$, table 2)., whereas total peritoneal BUN elimination was significantly higher in the CCPD group (4846.6 vs. $3393.4 \mathrm{mg}, \mathrm{p}<0.001$, table 2). Peritoneal cystatin $\mathrm{C}$ clearance was significantly higher in the CAPD group ( 9.9 vs. $7.0 \mathrm{l} / \mathrm{wk} / 1.73 \mathrm{~m}^{2}, \mathrm{p}<0.001$, table 2 ), whereas creatinine clearance was not significantly different ( 33.9 vs. $33.4 \mathrm{l} / \mathrm{wk} / 1.73 \mathrm{~m}^{2}, \mathrm{p}=0.450$, table 2). Peritoneal BUN clearance was higher in the CCPD group (52.1 vs. 38.9 l/wk/1.73 $\mathrm{m}^{2}, \mathrm{p}<0.001$, table 2). Serum albumin concentrations were not different between the two groups, the peritoneal loss of albumin was significantly higher in the CAPD than in the CCPD group ( 4.3 vs. $3.7 \mathrm{~g} / \mathrm{d}$, $\mathrm{p}=0.008)$, table 2 , figure 1 .

\section{Influence of peritoneal transport type on peritoneal substrate removal/clearance}

Since $24 / 26$ patients included in the study were high or high-average transport types we only analysed these two groups. In CCPD the transport type did not substantially influence the peritoneal clearance of any biomarker/albumin $(p>0.05$ for all parameters, table 3, 


\section{Kidney \\ Blood Pressure Research}

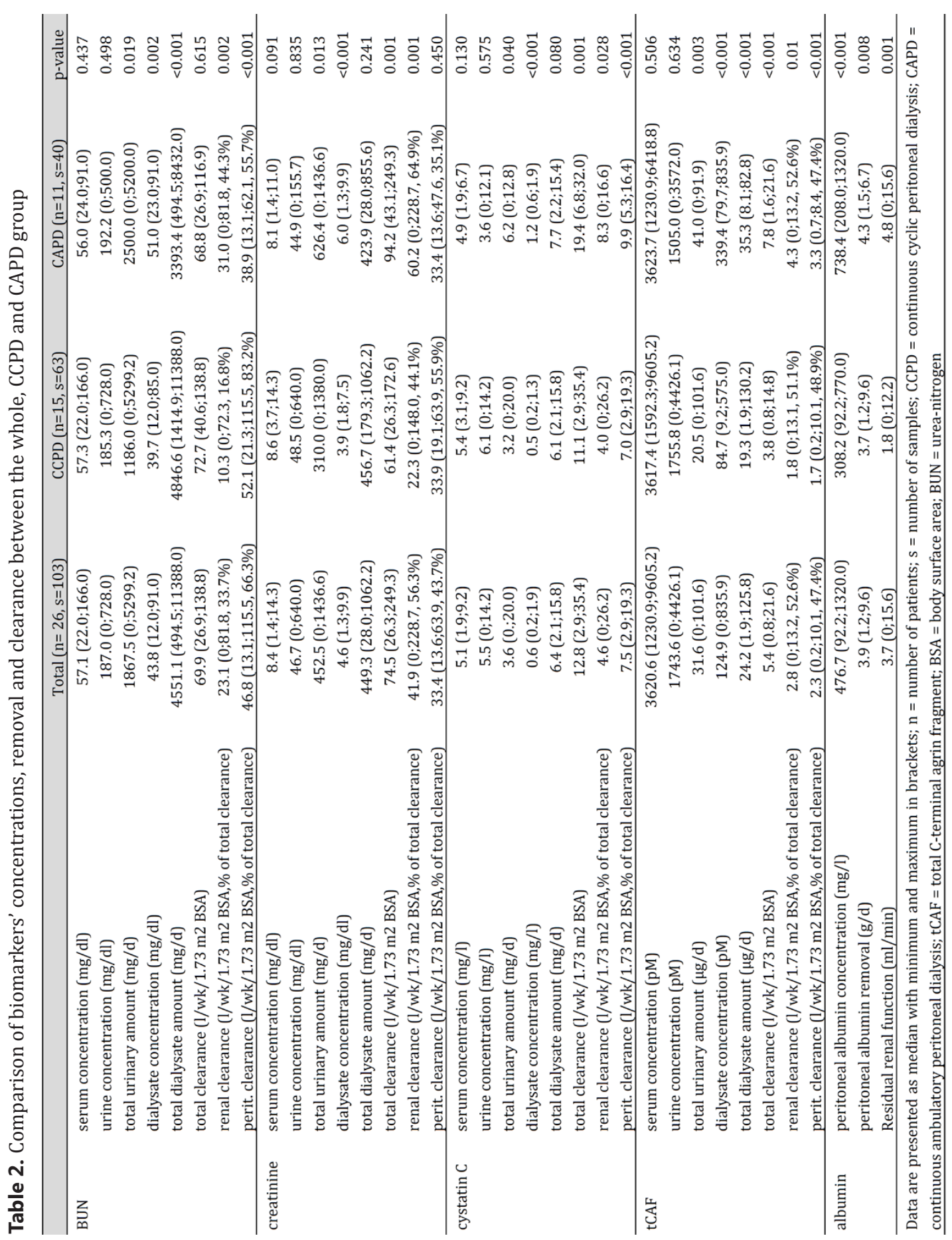

figure 2). In CAPD, BUN, Cr clearance and albumin removal did not differ between high and high-average transporters ( $p>0.05$ ), whereas tCAF and CyC clearance was significantly higher in high transporters ( $\mathrm{p}=0.002$ and $\mathrm{p}<0.001$ resp., table 3 , figure 2 ). Comparing CCPD and CAPD, in high-average transporters differences in biomarker clearance could only be detected for BUN in favour of CCPD (51.0 vs. $38.9 \mathrm{l} / \mathrm{wk} / 1.73 \mathrm{~m}^{2}, \mathrm{p}<0.001$, table 3). In hightransporters, BUN clearance was significantly higher in CCPD (54.2 vs. 38.4 l/wk/1.73 m², $\mathrm{p}<0.001$, table 3), whereas tCAF and CyC clearance was higher in CAPD (4.3 vs. 1.7 and 12.4 vs. $6.9 \mathrm{l} / \mathrm{wk} / 1.73 \mathrm{~m}^{2}, \mathrm{p}<0.001$ resp., table 3 ). 


\section{Kidney Blood Pressure Research}

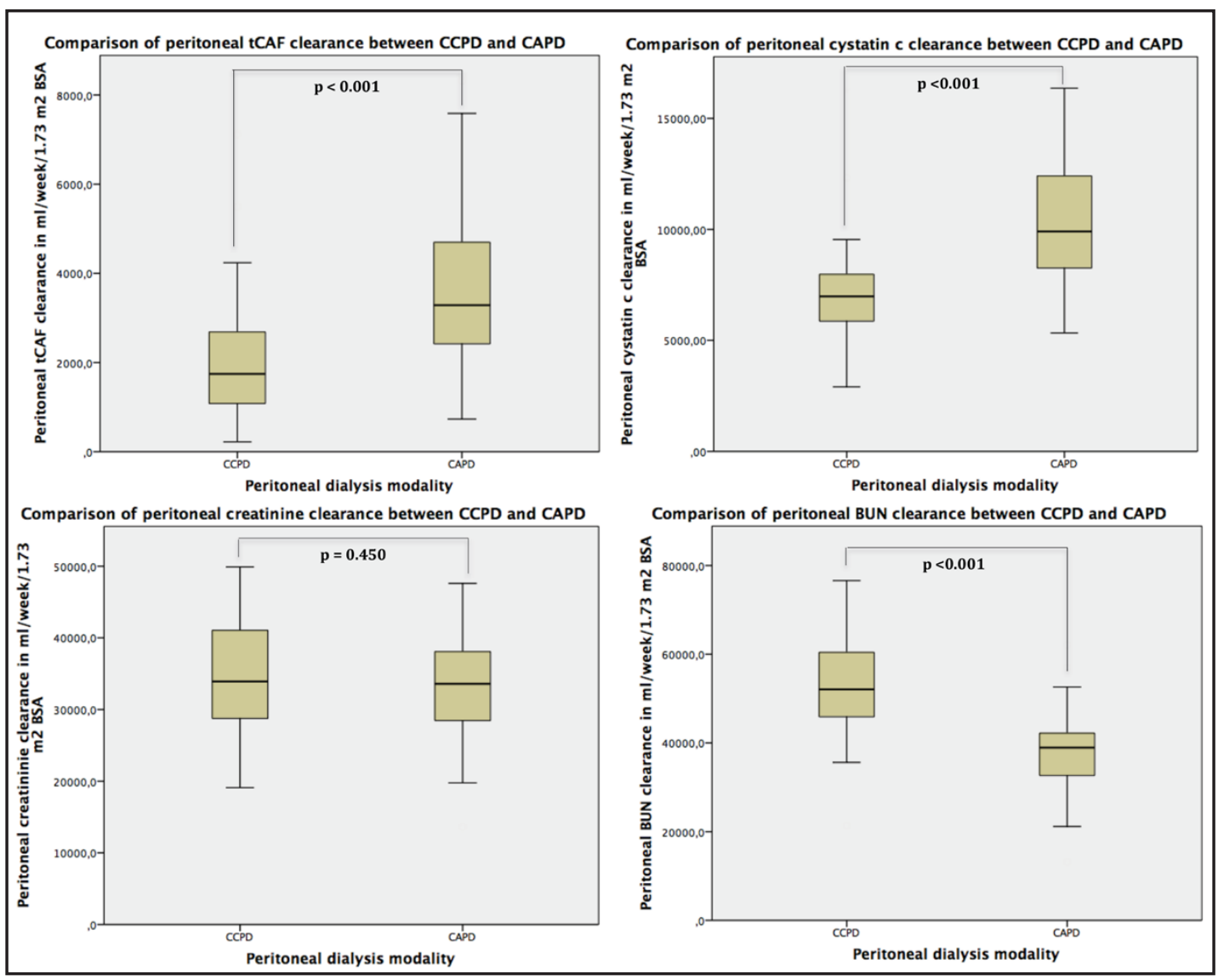

Fig. 1. Boxplots comparing the peritoneal clearance of different biomarkers between continuous cyclic peritoneal dialysis (CCPD) and continuous ambulatory peritoneal dialysis (CAPD); BSA = body surface area; $\mathrm{BUN}=$ blood-urea-nitrogen; $\mathrm{tCAF}=$ total C-terminal agrin fragment.

\section{Univariate/Multivariate linear regression analysis concerning peritoneal clearance}

In univariate linear regression, (log) tCAF clearance was significantly associated with the PD modality (standardized $\beta=0.464,95 \%$-CI $0.200-0.450, p<0.001$ ) at a $R^{2}=0.464$, expressing that $46 \%$ of tCAF clearance variation can be explained by PD modality. Whereas also albumin loss, cystatin $\mathrm{C}$ and BUN clearance were associated with PD modality (albumin: $\beta=0.236,95 \%$-CI $0.015-0.170, p=0.02$; cystatin C: $\beta=0.405,95 \%-C I \quad 0.078-0.209, p<0.001$; BUN: $\beta=-0.548,95 \%-C I-0.205-(-0.108), p<0.001)$, creatinine was not $(\beta=-0.126,95 \%-C I$ $-0.077-0.018, p=0.217)$. After adjustment for potential confounding factors in multivariate regression analysis, the association for tCAF remained significant $(\beta=0.430,95 \%$-CI $0.172-0.430, \mathrm{p}<0.001)$. $\mathrm{R}^{2}$ increased to 0.644 , indicating that around $64 \%$ of the variation can be explained with this model. Also albumin $(\beta=0.381,95 \%$-CI $0.069-0.232, \mathrm{p}<0.001)$, cystatin $C(\beta=0.362,95 \%$-CI $0.062-0.194, p<0.001)$ and BUN $(\beta=-0.365,95 \%-C I-0.150-(-$ $0.059), p<0.001)$ remained significantly associated with PD modality, results remained not significant for creatinine $(\beta=0.128,95 \%-C I-0.014-0.074, p=0.177)$.

\section{Discussion}

In this study we compared total, renal and peritoneal removal of non-protein-bound substances with different molecular masses from 60 up to 22.000 Dalton and peritoneal Alb loss between two modalities of PD, tidal CCPD and CAPD. 


\section{Kidney Blood Pressure Research}
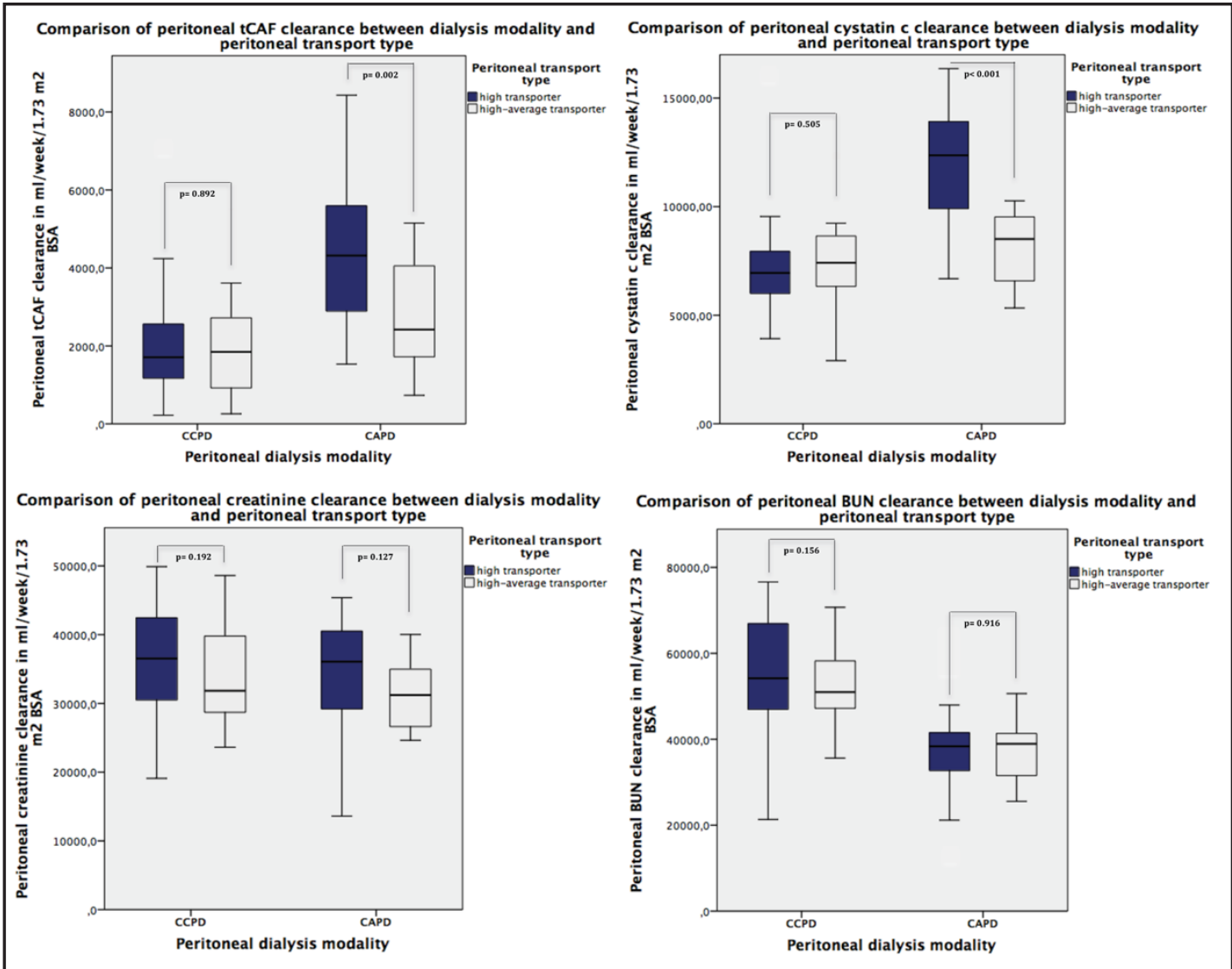

Fig.2. Boxplots comparing the peritoneal clearance of different biomarkers between continuous cyclic peritoneal dialysis (CCPD) and continuous ambulatory peritoneal dialysis (CAPD) as well as different transport types; $\mathrm{BSA}$ = body surface area; $\mathrm{BUN}$ = blood-urea-nitrogen; $\mathrm{tCAF}$ = C-terminal-agrin- fragment.

Whereas the peritoneal clearance was higher for BUN in CCPD it was significantly higher in CAPD for both LMWPs tCAF and CyC. The clearance was 1.4-fold in CAPD for CyC, while it was nearly 2 -fold for tCAF, indicating that the higher the molecular mass of the solute, the greater the difference between CAPD and CCPD. These significant differences persisted also after adjusting for multiple variables. The difference was predominantly due to differences in high-transporters, indicating that this subgroup of patients particularly benefits from CAPD treatment concerning LMWP removal. Finally, albumin loss was also higher in the CAPD group, but the difference was only 1.16-fold and did not influence serum albumin concentration. Renal clearance of tCAF was nearly 3-fold higher in CAPD patients due to higher RRF. It can be speculated that the difference in peritoneal tCAF clearance between CCPD and CAPD might have been even more pronounced in favour of CAPD treatment in groups with comparable RRF, since we could already show that higher RRF lowers the peritoneal contribution of tCAF clearance to total clearance [15]. It also needs to be addressed that our CAPD cohort had a median 24-h dialysate volume of 6 litres achieved with a median of 3 exchanges/day, which is below the usually used $4 \times 2-2.5 \mathrm{l} / \mathrm{d}$ and significantly less than the $11.5 \mathrm{l} / \mathrm{d}$ used in the CCPD group. So it can be assumed that peritoneal tCAF clearance might be even higher in CAPD regimens with higher dialysate volume. Actually, we did see a trend towards higher peritoneal clearance in CAPD patients with higher dialysate volume. In contrary, we did not assume that the addition of another exchange would substantially increase the peritoneal clearance of $\mathrm{tCAF}$, as in our experience the dialysate/serum quotient for tCAF is between 0.03 and 0.17 after a four hour dwell (unpublished data). To further evaluate this point we performed an analysis dividing our CAPD group into patients with 


\section{Kidney Blood Pressure Research}

Table 3. Comparison of biomarkers' concentrations, removal and clearance between CCPD and CAPD group in different transport types

\begin{tabular}{|c|c|c|c|c|}
\hline & Total $(n=98)$ & $\operatorname{CCPD}(n=59)$ & CAPD $(n=39)$ & $\mathrm{p}$-value \\
\hline high-transporter & $\mathrm{n}=54$ & $\mathrm{n}=31$ & $\mathrm{n}=23$ & \\
\hline Urea serum concentration $(\mathrm{mg} / \mathrm{dl})$ & $59.0(24.0 ; 99.0)$ & $63.5(43.0 ; 99.0)$ & $53.0(24.0 ; 91.0)$ & 0.022 \\
\hline Urea dialysate concentration (mg/dl) & $46.0(23.0 ; 91.0)$ & $45.0(27.0 ; 78.0)$ & $50.0(23.0 ; 91.0)$ & 0.470 \\
\hline Urea total dialysate amount $(\mathrm{mg})$ & $4726.5(494.5 ; 10530.0)$ & $5175.3(2107.0 ; 10530.0)$ & $3158.2(494.5 ; 5956.1)$ & $<0.001$ \\
\hline Urea perit. clearance $(\mathrm{l} / \mathrm{wk} / 1.73 \mathrm{~m} 2 \mathrm{BSA})$ & $47.2(13.1 ; 115.5)$ & $54.2(21.3 ; 115.5)$ & $38.4(13.1 ; 62.1)$ & $<0.001$ \\
\hline Creatinine serum concentration $(\mathrm{mg} / \mathrm{dl})$ & $8.6(1.4 ; 12.3)$ & $9.3(6.3 ; 12.3)$ & $8.0(1.4 ; 11.0)$ & 0.073 \\
\hline Creatinine dialysate concentration $(\mathrm{mg} / \mathrm{dl})$ & $4.8(1.3 ; 9.9)$ & $4.5(2.3 ; 6.4)$ & $6.1(1.3 ; 9.9)$ & 0.008 \\
\hline Creatinine total dialysate amount (mg) & $481.7(28.0 ; 917.7)$ & $485.5(250.6 ; 917.7)$ & $469.9(28.0 ; 810.0)$ & 0.419 \\
\hline Creatinine perit. cl. $(1 / \mathrm{wk} / 1.73 \mathrm{~m} 2 \mathrm{BSA})$ & $36.1(13.6 ; 63.9)$ & $36.5(19.1 ; 63.9)$ & $36.1(13.6 ; 45.4)$ & 0.355 \\
\hline Cystatin C serum concentration (mg/l) & $5.3(1.9 ; 9.2)$ & $5.6(4.0 ; 9.2)$ & $4.9(1.9 ; 6.4)$ & 0.005 \\
\hline Cystatin C dialysate concentration (mg/l) & $0.6(0.3 ; 1.9)$ & $0.5(0.3 ; 1.2)$ & $1.4(0.6 ; 1.9)$ & $<0.001$ \\
\hline Cystatin C total dialysate amount (mg) & $7.0(2.2 ; 15.8)$ & $6.3(2.6 ; 15.8)$ & $8.7(2.2 ; 15.4)$ & 0.029 \\
\hline Cystatin C perit. cl. (l/wk/1.73 m2 BSA) & $7.9(3.9 ; 19.3)$ & $6.9(3.9 ; 19.3)$ & $12.4(6.7 ; 16.4)$ & $<0.001$ \\
\hline tCAF serum concentration (pM) & $3791.0(1230.9 ; 9605.2)$ & $4066.3(1999.2 ; 9605.2)$ & $3653.1(1230.9 ; 5718.5)$ & 0.190 \\
\hline tCAF dialysate concentration $(\mathrm{pM})$ & $204.7(9.2 ; 835.9)$ & $89.8(9.2 ; 575.0)$ & $440.4(79.7 ; 835.9)$ & $<0.001$ \\
\hline tCAF total dialysate amount $(\mu \mathrm{g})$ & $27.7(1.9 ; 130.2)$ & $19.3(1.9 ; 130.2)$ & $49.8(15.4 ; 82.8)$ & 0.003 \\
\hline tCAF perit. clearance $(1 / w k / 1.73 \mathrm{~m} 2 \mathrm{BSA})$ & $2.7(0.2 ; 10.1)$ & $1.7(0.2 ; 10.1)$ & $4.3(1.5 ; 8.4)$ & $<0.001$ \\
\hline Albumin dialysate concentration (mg/l) & $483.0(124.0 ; 1320.0)$ & $333.0(124.0 ; 710.0)$ & $826.0(208.0 ; 1320.0)$ & $<0.001$ \\
\hline Albumin total dialysate amount (g) & $4.1(1.3 ; 9.6)$ & $3.6(1.3 ; 9.6)$ & $4.7(1.5 ; 6.7)$ & 0.154 \\
\hline high-average-transporter & $\mathrm{n}=44$ & $\mathrm{n}=28$ & $\mathrm{n}=16$ & \\
\hline Urea serum concentration $(\mathrm{mg} / \mathrm{dl})$ & $57.2(22.0 ; 166.0)$ & $52.5(22.0 ; 166.0)$ & $60.0(29.0 ; 80.0)$ & 0.708 \\
\hline Urea dialysate concentration (mg/dl) & $41.0(12.0 ; 85.0)$ & $37.3(12.0 ; 85.0)$ & $54.0(34.0 ; 81.0)$ & 0.002 \\
\hline Urea total dialysate amount $(\mathrm{mg})$ & $4415.2(1394.0 ; 11388.0)$ & $4530.5(1414.9 ; 11388.0)$ & $3313.65(1394.0 ; 5265.0)$ & 0.043 \\
\hline Urea perit. clearance $(1 / w k / 1.73 \mathrm{~m} 2 \mathrm{BSA})$ & $46.3(25.6 ; 70.7)$ & $51.0(35.6 ; 70.7)$ & $38.9(25.6 ; 50.6)$ & $<0.001$ \\
\hline Creatinine serum concentration $(\mathrm{mg} / \mathrm{dl})$ & $8.3(3.7 ; 14.3)$ & $8.5(3.7 ; 14.3)$ & $8.1(3.7 ; 10.3)$ & 0.376 \\
\hline Creatinine dialysate concentration $(\mathrm{mg} / \mathrm{dl})$ & $4.3(1.8 ; 8.3)$ & $3.3(1.8 ; 7.5)$ & $5.6(3.5 ; 8.3)$ & $<0.001$ \\
\hline Creatinine total dialysate amount $(\mathrm{mg})$ & $389.1(143.5 ; 1062.2)$ & $390.6(179.3 ; 1062.2)$ & $371.7(143.5 ; 700.8)$ & 0.144 \\
\hline Creatinine perit. cl. (1/wk/1.73 m2 BSA) & $31.6(23.6 ; 48.6)$ & $31.8(23.6 ; 48.6)$ & $31.2(24.6 ; 40.0)$ & 0.291 \\
\hline Cystatin C serum concentration (mg/l) & $5.0(2.7 ; 8.0)$ & $5.4(3.1 ; 8.0)$ & $4.8(2.7 ; 6.7)$ & 0.008 \\
\hline Cystatin C dialysate concentration (mg/l) & $0.6(0.2 ; 1.3)$ & $0.5(0.2 ; 1.3)$ & $1.1(0.6 ; 1.3)$ & $<0.001$ \\
\hline Cystatin C total dialysate amount (mg) & $6.2(2.7 ; 15.5)$ & $6.2(2.7 ; 15.5)$ & $5.0(3.7 ; 8.4)$ & 0.676 \\
\hline Cystatin C perit. cl. (l/wk/1.73 m2 BS.) & $7.5(2.9 ; 18.5)$ & $7.4(2.9 ; 18.5)$ & $8.5(5.3 ; 10.3)$ & 0.249 \\
\hline tCAF serum concentration $(\mathrm{pM})$ & $3689.0(1968.5 ; 6418.8)$ & $3713.3(2194.3 ; 6337.2)$ & $3660.1(1968.5 ; 6418.8)$ & 0.695 \\
\hline tCAF dialysate concentration (pM) & $113.9(10.9 ; 441.4)$ & $87.1(10.9 ; 326.3)$ & $216.7(80.6 ; 441.4)$ & $<0.001$ \\
\hline tCAF total dialysate amount $(\mu \mathrm{g})$ & $23.9(3.6 ; 79.2)$ & $22.4(3.6 ; 79.2)$ & $28.4(8.1 ; 54.6)$ & 0.135 \\
\hline tCAF perit. clearance $(1 / w k / 1.73 \mathrm{~m} 2 \mathrm{BSA})$ & $2.0(0.3 ; 5.5)$ & $1.8(0.3 ; 5.5)$ & $2.4(0.7 ; 5.1)$ & 0.100 \\
\hline Albumin dialysate concentration $(\mathrm{mg} / \mathrm{l})$ & $332.0(92.2 ; 925.0)$ & $244.5(92.2 ; 770.0)$ & $698.0(330.0 ; 925.0)$ & $<0.001$ \\
\hline Albumin total dialysate amount (g) & $3.4(1.2 ; 9.3)$ & $3.1(1.2 ; 9.3)$ & $4.3(2.4 ; 6.1)$ & 0.064 \\
\hline
\end{tabular}

4 exchanges/day and $<4$ exchanges/day (the latter using icodextrin twice per day, table 4 ). Whereas both groups significantly outperformed the CCPD group concerning peritoneal tCAF removal, the CAPD group with $<4$ exchanges/day had a significantly higher peritoneal tCAF clearance than the 4 exchange/day group ( 4.4 vs. $2.8 \mathrm{l} / \mathrm{wk} / 1.73 \mathrm{~m} 2 \mathrm{BSA}, \mathrm{p}<0.001$, table 4). Icodextrin has been shown to remove LMWPs more efficiently, probably due to better convective transport [19]. Still it has to be admitted that the number of high-transporter was greater in the $<4$ exchanges/day group. In support of our data, also Kim et al did not detect a positive influence on LMWP removal by increasing the number of exchanges [20].

High-transport type appears to be a crucial factor that explains the difference of peritoneal tCAF removal, since this subgroup particularly had a benefit from CAPD treatment, whereas high-average transporter did not. Surprisingly the transport type did not influence LMWP clearances in CCPD patients despite a daily filling with Icodextrin. Therefore it can be stated that the peritoneal transport type cannot exclusively explain tCAF elimination but the treatment modality appears to play an important role. Again the difference was more pronounced for tCAF compared to CyC. However, albumin removal was not substantially influenced by transport type. Al-Wakeel et al stated that $\mathrm{CyC}$ removal behaves the same way as $\mathrm{Cr}$, but transport type has lower impact on $\mathrm{CyC}$ than on $\mathrm{Cr}$ [21]; a finding that is contradictory to our results. 


\section{Kidney Blood Pressure Research}

Table 4. Demographic parameters and comparison of tCAF concentrations, removal and clearance between CCPD, CAPD patients with 4 exchanges and $<4$ exchanges per day

\begin{tabular}{|c|c|c|c|}
\hline & CCPD (n=15, s=63) & CAPD $4 / d(n=6, s=21)$ & CAPD $<4 / d(n=5, s=19)$ \\
\hline Number of samples per patient (n) & $4.5(1 ; 7)$ & $3(2 ; 5)$ & $4(3 ; 6)$ \\
\hline Ages (years) & $53(42 ; 89)$ & $61(43 ; 65)$ & $61(48 ; 64)$ \\
\hline Gender (male/female) & $8 / 7$ & $3 / 3$ & $1 / 4$ \\
\hline Distribution volume (l) & $39.4(26.1 ; 49.5)$ & $42.7(26.8 ; 63.3)$ & $32.9(21.5 ; 37.3)$ \\
\hline Body surface area $\left(\mathrm{m}^{2}\right)$ & $1.9(1.4 ; 2.2)$ & $2.0(1.5 ; 2.6)$ & $1.8(1.2 ; 1.9)$ \\
\hline Peritoneal transport type (H/HA/LA/L) & $7 / 7 / 1 / 0$ & $2 / 3 / 1 / 0$ & $3 / 2 / 0 / 0$ \\
\hline \multicolumn{4}{|l|}{ tCAF } \\
\hline serum concentration $(\mathrm{pM})$ & $3617.4(1592.3 ; 9605.2)^{*}$ & $3773.3(2906.7 ; 5294.3)^{\#}$ & $3326.1(1230.9 ; 5700.1)^{*}$, \# \\
\hline urine co & $1755.8(0 ; 4426.1)$ & $1552.6(0 ; 3$ & $1367.5(0 ; 24$ \\
\hline total urinary amount $(\mu \mathrm{g})$ & $20.5(0 ; 101.6)^{\S}$ & $50.5(0 ; 91.9)^{\S}$ & $39.8(0 ; 85.1)$ \\
\hline dialysate concentration (pM) & $84.7(9.2 ; 575.0)^{*}, \S$ & $255.3(117.4 ; 488.1)^{\S, \#}$ & $440.4(80.6 ; 835.9)^{*}, \#$ \\
\hline total dialysate amount $(\mu \mathrm{g})$ & $19.3(1.9 ; 130.2)^{*}, \S$ & $34.1(18.0 ; 75.5)^{\S}$ & $39.9(8.1 ; 82.8)^{*}$ \\
\hline total clearance $(\mathrm{l} / \mathrm{wk} / 1.73 \mathrm{~m} 2 \mathrm{BSA})$ & $3.8(0.8 ; 14.8)^{*}, \S$ & $7.8(2.3 ; 11.0)^{\S}$ & $9.3(1.6 ; 21.6)^{*}$ \\
\hline renal clearance (l/wk/1.73 m2 BSA,\% of total clearance) & $1.8(0 ; 13.1,51.1 \%)^{*}, \S$ & $4.5(0 ; 6.9 ; 52.4 \%)^{\S}$ & $4.8(0 ; 13.2,53.3 \%)^{*}$ \\
\hline perit. clearance $(\mathrm{l} / \mathrm{wk} / 1.73 \mathrm{~m} 2 \mathrm{BSA}, \%$ of total clearance) & $1.7(0.2 ; 10.1,48.9 \%)^{*}, \S$ & $2.8(1.5 ; 5.6 ; 47.6 \%)^{\S . \#}$ & $4.4(0.7 ; 8.4,46.7 \%)^{*}, \#$ \\
\hline \multicolumn{4}{|c|}{ 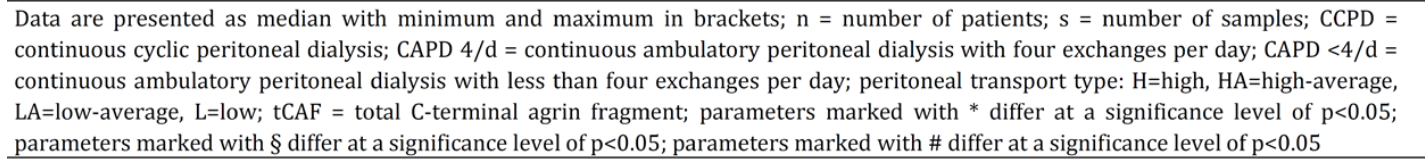 } \\
\hline
\end{tabular}

Earlier studies could not detect a difference in LMWP clearance between APD and CAPD patients $[13,22]$. However, in both studies no patients with high-transporter status were included (resp. one in the study of Evenepoel), the group of patients for which we showed the most pronounced differences concerning peritoneal tCAF removal. In regard to high-average transport types we could reproduce the results of both studies with nonsignificant differences. In summary, we do not consider our results to be contradictory to the observations from earlier studies. However, it has to be kept in mind that our results were not gathered from a cross-over controlled trial.

We were aware that including 103 sets of samples gathered from 26 patients could bias our results. Therefore we also evaluated only one randomly selected set of samples of each patient. Whereas the peritoneal clearance between CCPD and CAPD did not significantly differ regarding BUN and $\mathrm{Cr}$, it remained significant for $\mathrm{CyC}$ and $\mathrm{tCAF}$ in CAPD.

The explanation for the difference of peritoneal large LMWP removal is most likely based on different diffusive and convective abilities of molecules based on molecular radius [23]: Arbeiter et al demonstrated a linear increase of LMWP elimination over a 4h-period in a peritoneal equilibration test (PET), whereas an equilibration between serum and dialysate for BUN is already reached after one hour. Kabanda et al demonstrated a similar finding of a steep decrease of peritoneal clearance for proteins with a molecular mass between 13 and $26 \mathrm{kDa}$ [24]. It was discussed that clearance of proteins on the upper range of the scale even more rely on long dwell times compared to smaller ones. Yamamoto et al demonstrated an inverse correlation between peritoneal small solute clearance and beta-2-microglobulin serum concentrations, indicating that shorter dwell times impede the elimination of LMWP [25].

Another fact that needs to be addressed is that despite higher renal and peritoneal removal of $\mathrm{tCAF}$ in CAPD patients serum concentrations were comparable to those in CCPD patients, as one might expect lower serum concentrations with higher removal. However, in our study also creatinine and cystatin $\mathrm{C}$ concentrations did not differ substantially despite higher total substance removal of both parameters in CAPD. Therefore it has to be stated that serum concentrations are inaccurately correlated to dialysis dose, as it has been also shown for cystatin $\mathrm{C}$ and p-cresol in hemodialysis and peritoneal dialysis patients, respectively [22, 26]. Possibly the production rate of tCAF is adapted to removal; the origin of tCAF in the blood is rather from non-neuronal tissue, since both agrin (the substrate tCAF is generated from) and neurotrypsin (the enzyme splicing agrin so that tCAF is generated) can be found in various organs (personal communication Hettwer S, Neurotune AG). However, to elucidate 


\section{Kidney \\ Blood Pressure Research}

Kidney Blood Press Res 2016;41:175-185

\begin{tabular}{l|l}
\hline DOI: 10.1159/000443419 & (C) 2016 The Author(s). Published by S. Karger AG, Basel
\end{tabular}

Published online: March 10, 2016

www.karger.com/kbr

Steubl/Roos/Hettwer/Angermann/Wen/Schmaderer/Luppa/Heemann/Renders: LMWP

Clearance in CAPD vs. CCPD

this finding is beyond the scope of this article and needs further evaluation in basic science related studies, e.g. tissue-specific neurotrypsin knock-out mouse models.

Our study has some limitations: The number of study participants is rather small and we gathered 103 samples in 26 patients, a circumstance that might lead to a sample collection bias. Therefore we conducted an analysis implying only one sample of each patient. The study was not conducted in a cross-over design, so we cannot be sure that differences exist between the two groups that might influence the results, although we accounted for that fact by performing multivariate regression analysis. In CCPD patients, samples were collected after complete termination of the procedure, so possibly small amounts of unused dialysate from flush or the heating bag might have been drained into the collection bag. Therefore differences between clearance rates and total solute removal might exist.

\section{Conclusion}

We could show that CAPD outperforms CCPD concerning LMWP clearance. tCAF as a marker for LMWPs exceeding a molecular mass of $20 \mathrm{kDa}$ was even more effectively eliminated by CAPD compared to cystatin $\mathrm{C}$, indicating that with increasing molecular mass the advantage of CAPD over CCPD becomes more pronounced. According to our study this is predominantly seen in peritoneal high transporters, also increased convective transport mediated by the use of icodextrin twice per day contributed to LMWP removal. If these findings result into advantages concerning morbidity or mortality needs to be addressed in future studies.

\section{Disclosure Statement}

Stefan Hettwer is currently employed by Neurotune AG, Schlieren, Switzerland. The remaining authors of this manuscript have no conflicts of interest to disclose as described by the journal. All authors have read the journal's policy on conflicts of interest. Furthermore, all authors have read the journal's authorship agreement. the results presented in this paper have not been published previously in whole or part, except in abstract format.

\section{Acknowledgements}

This work was supported by the German Research Foundation (DFG) and the Technische Universität München within the funding programme Open Access Publishing.

\section{References}

1 Burkhalter F, Steiger J, Dickenmann M: A road map for patients with in imminent end-stage renal disease. Swiss Med Wkly 2012;142:w13713.

2 Michels WM, Verduijn M, Boeschofen EW, Dekker FW, Krediet FW; NECOSAD Study Group: Similar survival on automated peritoneal dialysis and continuous ambulatory peritoneal dialysis in a large prospective cohort. Clin J Am Soc Nephrol 2009;4:943-949.

3 Cnossen TT, Usvyat L, Kotanko P, van der Sande FM, Kooman JP, Carter M, Leunissen KM, Levin NW: Perit Dial Int 2011;31:679-684.

4 Balasubramanian G, McKitty K, Fan SL: Comparing automated peritoneal dialysis with continuous ambulatory peritoneal dialysis: survival and quality of life differences? Nephrol Dial Transplant 2011;26:1702-1708.

5 Rodriguez-Carmona A, Perez-Fontán M, Garca-Naveiro R, Villaverde P, Peteiro J: Compared time profiles of ultrafiltration, sodium removal, and renal function in incident CAPD and automated peritoneal dialysis patients. Am J Kid Dis 2004;44:132-145. 


\section{Kidney \\ Blood Pressure Research}

Kidney Blood Press Res 2016;41:175-185

\begin{tabular}{l|l}
\hline DOI: 10.1159/000443419 & (C) 2016 The Author(s). Published by S. Karger AG, Basel
\end{tabular}

Published online: March 10, 2016

www.karger.com/kb

6 Rodriguez-Carmona A, Fontán MP: Sodium removal in patients undergoing CAPD and automated peritoneal dialysis. Perit Dial Int 2002;22:705-713.

7 Roszkowska-Blaim M, Skrzypczyk P, Jander A, Tkaczyk M, Balasz-Chmielewska I, Zurowska A, Drozdz D, Pietrzyk JA: The effect of peritoneal dialysis method on residual renal function in children. Adv Perit Dial 2012;28:112-119.

8 Vanholder R, De Smet R, Glorieux G, Argilés A, Baurmeister U, Brunet P, Clark W, Cohen G, De Deyn PP, Deppisch R, Descamps-Latscha B, Henle T, Jörres A, Lemke HD, Massy ZA, Passlick-Deetjen J, Rodriguez M, Stegmayr B, Stenvinkel P, Tetta C, Wanner C, Zidek W; European Uremic Toxin Work Group (EUTox): Review on uremic toxins: Classification, concentration, and in- terindividual variability. Kidney Int 2003;63:19341943.

9 Bargman JM: Rethinking the peritoneal dialysis prescription: results of recent studies. Nephrology (Carlton) 2006;11:85-89.

10 Hiroshige K, Yuu K, Soejima M, Takasugi M, Kuroiwa A: Rapid decline of residual renal function in patients on automated peritoneal dialysis. Perit Dial Int 1996;16:307-315.

11 Bammens B, Evenepoel P, Verbeke K, Vanrenterghem Y: Removal of middle molecules and protein-bound solutes by peritoneal dialysis and relation with uremic symptoms. Kidney Int 2003;64:2238-2243.

12 Montini G, Amici G, Milan S, Mussap M, Naturale M, Ratsch I, Ammenti A, Sorino P, Verrina E, Andreeta B, Zaccarello G: Middle molecule and small protein removal in children on peritoneal dialysis. Kidney Int 2002;61:1153-1159.

13 Eloot S, Vanholder R, Dequidt C, Van Biesen W: Removal of different classes of uremic toxins in apd vs capd: a randomized cross-over study. Perit Dial Int 2015;35:436-442.

14 Steubl D, Hettwer S, Vrijbloed W, Dahinden P, Wolf P, Luppa P, Wagner CA, Renders L, Heemann U, Roos M: C-terminal agrin fragment (CAF) - a new fast biomarker for kidney function in renal transplant recipients. Am J Nephrol 2013;38:501-508.

15 Steubl D, Hettwer S, Dahinden P, Luppa P, Rondak IC, Regenbogen C, Stock KF, Renders L, Heemann U, Roos M: C-terminal agrin fragment (CAF) as a serum biomarker for residual renal function in peritoneal dialysis patients. Int Urol Nephrol 2015;47:391-396.

16 http://www.neurotune.com/downloads.html

17 Twardowski ZJ, Nolph KD, Khanna R, Prowant BF, Ryan LP, Moore HL, Nielsen MP: Peritoneal equilibration test. Perit Dial Bull 1987; 7:138-147.

18 La Milia V, Pozzoni P, Virga G, Crepaldi M, Del Vecchio L, Andrulli S, Locatelli F: Peritoneal transport assessment by peritoneal equilibration test with $3.86 \%$ glucose: a long-term prospective evaluation. Kidney Int 2006;69:927-933.

19 Ho-dac-Pannekeet MM, Schouten N, Langendijk MJ, Hiralall JK, de Waart DR, Struijk DG, Krediet RT: Peritoneal transport characteristics with glucose polymer based dialysate. Kidney Int 1996;50:979-986.

20 Kim DJ, Do JH, Huh W, Kim YG, Oh HY: Dissociation between clearances of small and middle molecules in incremental peritoneal dialysis. Perit Dial Int 2001;21:462-466.

21 Al-Wakeel JS, Hammad D, Memon NA, Tarif N, Shah I, Chaudhary A, Saudi J: Serum cystatin C: a surrogate marker for the characteristics of peritoneal membrane in dialysis patients. Kidney Dis Transpl 2009;20:227231.

22 Evenepoel P, Bammens B, Verbeke K, Vanrenterghem Y: Superior dialytic clearance of beta(2)-microglobulin and p-cresol by high-flux hemodialysis as compared to peritoneal dialysis. Kidney Int 2006;70: 94-799.

23 Arbeiter K, Stemberger R, Greenbaum L, Mueller T, Konstantin A, Herkner K, Aufricht C: Peritoneal transport kinetics of proteins in children on chronic peritoneal dialysis. Perit Dial Int 2003;23:162-168.

24 Kabanda A, Goffin E, Bernard A, Lauwerys R, van Ypersele de Strihou C: Factors influencing serum levels and peritoneal clearances of low molecular weight proteins in continuous ambulatory peritoneal dialysis. Kidney Int 1995;48:1946-1952.

25 Yamamoto S, Kasai A, Shimada H: High Peritoneal Clearance of small molecules did not provide low serum ß2-microglobulin concentrations in peritoneal dialysis patients. Perit Dial Int 2003;23:S34-S36.

26 Huang SH, Filler G, Yasin A, Lindsay RM: Cystatin C reduction ratio depends on normalized blood liters processed and fluid removal during hemodialysis. Clin J Am Soc Nephrol 2011;6:319-325. 